\begin{tabular}{|c|c|c|}
\hline $\begin{array}{l}\text { PKS } \\
\text { PUBLIC } \\
\text { KNNDLEDGE } \\
\text { RROJECT }\end{array}$ & $\begin{array}{c}\text { REVISTA DE GEOGRAFIA } \\
\text { (RECIFE) } \\
\text { http://www.revista.ufpe.br/revistageografia }\end{array}$ & $\begin{array}{l}\text { OJS } \\
\text { OJEN } \\
\text { JOUNAL } \\
\text { SYSTEMS }\end{array}$ \\
\hline
\end{tabular}

\title{
TERRITÓRIOS E TERRAS INDÍGENAS: UMA BREVE REFLEXÃO A PARTIR DA GEOGRAFIA
}

\author{
Maria Bárbara Magalhães Bethonico ${ }^{1}$ \\ ${ }^{1}$ Doutora em Geografia, Professora do Instituto Insikiran de Formação Superior Indígena - \\ Curso de Gestão Territorial Indígena - Professora dos programas de pós-graduação: \\ Geografia/PPGGEO e Recursos Naturais/PRONAT. E-mail: maria.bethonico@ufrr.br
}

Artigo recebido em 04/09/2017 e aceito em 23/01/2018.

\begin{abstract}
Resumo
Os povos indígenas têm em seu histórico deslocamentos e a formação de novos territórios e os motivos para essa dinâmica são diversos. Com a chegada do Estado Nacional e sua lógica capitalista, essa dinâmica tem se alterado com a demarcação de terras indígenas, principalmente na Amazônia, destinando aos povos um espaço para sua sobrevivência e reprodução física e cultural, como definido no texto constitucional brasileiro. Trazemos aqui uma reflexão e uma colaboração sobre o conceito de terra indígena e território indígena, considerando uma experiência profissional que se depara constantemente com a dúvida de como se referir aos atuais espaços destinados a esses povos: terra indígena ou território indígena. Discutimos que, em um momento anterior a expansão capitalista, os povos indígenas se deslocavam pelo espaço e se apropriavam de novas áreas, constituindo novos territórios e áreas de controle. No século XX, o Estado define que algumas áreas devem ser demarcadas, criando as terras indígenas. Essas ações indicam um avanço para esses povos, porém, essas terras são, ao mesmo tempo, uma garantia à reprodução do grupo e uma limitação no que se refere ao controle do espaço, tanto no uso dos recursos naturais quanto na disposição da própria terra, que é controlada pelo Estado e não pelas comunidades.
\end{abstract}

Palavras-chave: território; Estado; terra indígena; Amazônia.

\section{TERRITORIES AND INDIGENOUS LANDS: A BRIEF REFLECTION FROM GEOGRAPHY}

\begin{abstract}
The indigenous peoples have in their historical displacement and the formation of new territories with diverse reasons. Within the arrival of National State and its capital logic. This dynamic has altered with indigenous lands' demarcation, mainly in Amazon, based on a space where peoples could survive, physical and cultural reproduction, as defined in the Brazilian constitutional text. Here we illustrate a reflection and consideration on the concept of indigenous land and indigenous territory, considering a professional experience which is constantly encountered with this question of how to refer the current spaces destined to these people: indigenous land and indigenous territory. We discussed that, at a time prior to the capitalist expansion, indigenous peoples moved through space and appropriated new areas, constituting new territories and areas of control. In the twentieth century, the state defined that some areas should be demarcated, creating indigenous lands. This action indicates an advance for these peoples, therefore, these lands, are at the same time, a guarantee to the reproduction of the group and a limitation with respect to the control of the space, as much in the use of the natural resources as in the disposition of its own land, It is controlled by the state and not by its communities.
\end{abstract}

Keywords: territory; State; Indigenous land; Amazonia. 


\section{INTRODUÇÃO}

No ano de 2015 em um momento com os índios Macuxi moradores da comunidade Pedra Preta, localizada às margens do rio Cotingo na Terra Indígena Raposa Serra do Sol, levantou-se o questionamento sobre a diferença entre terra e território indígena. Pergunta pertinente e comum em salas de aula com alunos indígenas que frequentam os cursos de graduação oferecidos pelo Instituto Insikiran na Universidade Federal de Roraima, e entre vários moradores das comunidades. A dúvida refere-se ao termo mais apropriado para se referir ao local onde habitam e sobrevivem. Surge, muitas vezes, a ideia de que são termos sinônimos e, portanto, podem ser utilizados sempre para referirem-se ao espaço demarcado pelo Estado e onde desenvolvem suas atividades e reprodução física e cultural atualmente. Outra dúvida que permeia esse campo é sobre se as terras que foram demarcadas com limites pequenos, se contrapondo a extensões maiores, como a Terra Indígena Yanomami, devem receber a denominação de "terras em ilha" ou "territórios em ilha", aparecendo, novamente, a dúvida sobre os conceitos de terra e território. Diante destes questionamentos e dúvidas, o objetivo deste artigo é discutir os conceitos de terra indígena e território indígena com reflexões iniciais e o propósito de instigar o debate. Para tal teremos como base o estado de Roraima com suas trinta e duas terras indígenas que abrigam os povos das etnias Macuxi, Wapichana, Taurepang, Patamona, Ingaricó, Yanomami, Wai-Wai, Ye'kuana. A ciência geográfica será a norteadora dessas reflexões, algumas vezes com diálogos com outras áreas, como a Antropologia, mediada por aspectos da historiografia roraimense e dados secundários que contribuirão para as ideias aqui colocadas.

As reflexões partiram de um levantamento bibliográfico que permitiu a análise de dados secundários, complementados pelas observações que ocorreram em ações em diversas comunidades indígenas ao longo do trabalho junto a estudantes universitários indígenas da Universidade Federal de Roraima. Acreditamos que as discussões aqui apresentadas podem contribuir para pesquisas futuras que abordam questões indígenas e de seus territórios ou terras, cientes de que são reflexões iniciais e que muito deve ser escrito para afinarmos os conceitos de terra indígena e território indígena. O artigo está dividido em três partes, iniciando com a abordagem do conceito de território e território indígena dentro de uma abordagem geográfica; em seguida buscamos oferecer alguns aspectos relevantes para a existências das terras indígenas no Brasil para, ao final, apresentar as terras indígenas de 
Roraima e alguns de seus aspectos.

\section{1 - TERRITÓRIO E TERRITÓRIO INDÍGENA}

Pensar o espaço geográfico é algo complexo e, por isso, a Geografia foi, ao longo dos tempos, cunhando conceitos capazes de compreender essa complexidade. O início dessa complexidade está na própria concepção de espaço, isto é, o lugar onde moramos, onde habitamos, onde o homem constrói seus meios de sobrevivência, o próprio planeta Terra que é, por si só, complexo. De acordo com Dantas (2004), a raiz da complexidade está na relação entre natureza e cultura, mesmo que essa complexidade venha a causar alguns questionamentos sobre o que é realmente o objeto da Geografia.

Faz parte das análises geográficas as descrições, os detalhamentos nas classificações, os elementos da natureza e sua interdependência e, sobretudo, a ação do homem sobre essa natureza. Realizamos um esforço cognitivo para compreender as relações que se realizam através das observações, da explicação, da comparação, enfim, das territorialidades que se constituem ao longo da história das sociedades. Destaca-se a necessidade de dialogar com outras áreas do conhecimento, considerando, principalmente, que vivemos em um mundo dinâmico, com várias paisagens e cenários culturais, sociais, políticos e econômicos, bem como com diferentes visões sobre a natureza e a relação que devemos estabelecer com ela. Assim, defende Dantas (2004), a Geografia terá que alargar seu campo teórico-metodológico para atingir a necessária religação dos conceitos, ideias e procedimentos, e poderá prosseguir como ciência narrativa do espaço.

Em outra discussão, Roux (2004) aborda o território a partir da concepção de complexidade, onde os atores de um território devem se tornar seres preocupados com o bem comum, principalmente quando abordamos situações onde o capitalismo está presente e que a sociedade de consumo desterritorializa vários grupos em nome do progresso, eliminando tradições e os territórios de origem, como é o caso dos povos indígenas, principalmente quando falamos de uma expansão da fronteira agrícola e de "ocupação" da Amazônia, desconsiderando os povos que a habitam por séculos. Essa desterritorialização levou várias sociedades indígenas a criarem novos territórios ou buscarem outras áreas, novos referenciais culturais de forma a adaptarem-se a uma nova realidade. Para o autor, é urgente rever os 
modos de pensar ao planejar o território, de forma a romper com práticas políticas, geográficas e administrativas que são usadas e prestar mais atenção nas críticas e, nesse sentido, a complexidade ajuda nas reflexões.

Entre os elementos dessa complexidade, temos o território. Todos os homens estão inseridos em um espaço geográfico, sendo este a base de sua sobrevivência material, social, política e cultural. O espaço é a base de toda a discussão geográfica e somente a partir dele configuram-se os territórios e, assim, "o território se forma a partir do espaço, é o resultado de uma ação conduzida por um ator sintagmático em qualquer nível. Ao se apropriar de um espaço, concreta ou abstratamente (por exemplo, pela representação), o ator 'territorializa' o espaço" (RAFFESTIN, 1993, p. 143). Essa apropriação do espaço refere-se ao uso de um determinado poder em um espaço geográfico. Os homens atribuem algum tipo de poder às coisas, a outros homens ou a si mesmos. Para analisar uma realidade é fundamental buscar a compreensão desse poder, ou poderes, que encontram-se no espaço, sem desconsiderar o aspecto tempo, contextualizando a formação/constituição das relações mediadas sempre pelo poder.

O conceito de território é usado por várias áreas do conhecimento (Economia, Sociologia, Biologia), inclusive a Geografia que trata, hoje, como um conceito que se expande além do simples ordenamento espacial. Segundo Moine (2006), o conceito de território se tornou expressivo por representar a complexidade que nos rodeia, além do espaço físico, natural e paisagístico, mas concretiza-se quando os homens passam a habitá-lo e apropriar-se dele. Considera que, para a constituição de um território, a referência espacial é central, um espaço social e vivido; é o espaço apropriado através de sentimentos de pertencimento construídos ao longo da história e das relações humanas que se mantém em um local. A definição do termo território tem como base o conceito de propriedade, de administração, de controle e gestão de um espaço muito claramente definido. A constituição de um território não está ligada, necessariamente, aonde se nasce, mas ao local onde se vive e onde se constroem ligações que colocam um sistema familiar em equilíbrio e dentro de um sistema local. Diante das incertezas, busca-se um ambiente controlado, conhecido, onde os atores estabelecem inúmeras relações entre eles e entre os objetos dispostos no espaço geográfico (MOINE, 2006).

Ao pensar em quem pode exercer o poder sobre um espaço, Raffestin (1993) aponta que os atores que praticam o poder saem da população, e as ações vinculadas a esse poder é 
que produzem o território, produto dos atores sociais que partem de uma realidade espacial específica. O poder é inevitável, sem inocência e que vai marcar todas as relações em uma determinada sociedade.

Os homens necessitam de um território para viver. Nesse sentido, pensar grupos humanos sem territórios é um mito, como bem destaca Haesbaert (2004). A perda de um território por um grupo significa a possibilidade de reconstruir o território em outro local e, a partir dele, reconstruir as novas bases e territorialidades. No caso dos indígenas o processo de expansão do Estado e as novas fronteiras capitalistas levaram a essa necessária reconstrução do território em um local com presença de recursos naturais capazes de garantir a sobrevivência do grupo. Contrapondo-se aos que falam do fim dos territórios, existe a defesa pela continuidade do território. O enfraquecimento da mediação espacial e material nas relações sociais é questionável, uma vez que não faltam processos que:

\begin{abstract}
reenfatizam uma base geográfica, material, a começar pelos que envolvem questões ecológicas (desflorestamento, erosão, poluição, efeito estufa) e de acesso a novos recursos naturais (como aqueles ligados à biodiversidade), questões ditas demográficas e de difusão de epidemias, questões de fronteira e controle da acessibilidade (como nos fluxos migratórios), novas lutas nacional-regionalistas de forte base territorial etc. (HAESBAERT, 2004, p. 25).
\end{abstract}

Santos (2005) propõe que o espaço geográfico é sinônimo de território usado e que este é indispensável para a compreensão do mundo em que vivemos e seu funcionamento. Para o autor, antes o Estado definia os territórios, isto é, os territórios estavam subordinados e moldados pelo Estado, compondo sua base e o fundamento da nação. Hoje temos uma outra realidade, onde o território se transnacionaliza, porém nem tudo é totalmente estatizado e nem todo território é transnacionalizado. Nesse sentido, "mesmo nos lugares onde os vetores da mundialização são mais operantes e eficazes, o território habitado cria novas sinergias e acaba por impor, ao mundo, uma revanche. Seu papel ativo faz-nos pensar no início da História, ainda que nada seja como antes" (SANTOS, 2005, p. 255).

No caso dos territórios indígenas a sua criação não está, pelo menos inicialmente, vinculada a uma decisão do Estado, quando consideramos os momentos em que as fronteiras nacionais ainda não estavam definidas ou que o Estado ainda não tinha preocupação com a organização territorial como ocorreu com as áreas mais remotas da Amazônia. Nestes momentos as sociedades indígenas se locomoviam por vários espaços sem a preocupação com os limites ou fronteiras estatais. Ao refletir sobre a concepção de território para o povo 
indígena Ye'kuana, Silva (2017) destaca que o espaço habitado por eles é considerado como a fonte da vida, de onde retiram o sustento de sua família e onde os ancestrais deixaram suas marcas. Para o autor,

Os Ye'kuana são originários da cabeceira do rio Kuntanaama, localizado fronteira Brasil/Venezuela, região do rio Kuntanaama, na Serra Ye'kuana. Conforme a wätunnä, o primeiro Ye'kuana a chegar nesta terra foi na região da cabeceira do rio Kuntunama, e chamava-se Yuduwaana, mais precisamente na Serra do Ye'kuana [...] Um dos heróis míticos Ye'kuana, o Kuyujani, demarcou uma área Ye'kuana, segundo o wätunnä. A partir disso, os Ye'kuana consideram o seu território tradicional, o espaço onde eles podem viver, habitar e implantar novas comunidades (SILVA, 2017, p. 39-40).

Atualmente, e desde os tempos imemoriais, os Ye'kuana ocupam a região das cabeceiras dos rios Cunucunuma, Padamo, Cuntinamo, Ventuari e Metecuni e Medewadi (afluentes do Orinoco) na Venezuela, e do rio Auaris (afluente do rio Uraricoera) no Brasil. Para os Ye'kuana o território não é um espaço vazio, mas habitado, também, por espíritos bons e ruins, os seres invisíveis que podem estar em qualquer lugar desse espaço (na água, na terra ou nas serras), indicando que todos os elementos da natureza tem seus "donos" e compõem o território junto aos homens que ali vivem (SILVA, 2017).

O território para um indígena significa, dessa forma, um local em que consegue suprir suas necessidades (caça, roça, pesca) e que domina ou controla, além de ter bem claro os limites desse território diante de outros grupos étnicos ou comunidades. Quando necessitam usar algum elemento (recurso) que encontra-se no território do outro, é necessário solicitar autorização. Isso ocorre tanto com os Ye'kuana, quanto com os Macuxi e outros povos que habitam essa porção norte da Amazônia.

Fatores externos podem ocasionar o deslocamento de grupos que acabam por construir um novo território. Quando a borracha começou a ser extraída da área venezuelana onde habitavam, os Ye'kuana, devido às condições de exploração que sofreram, buscaram novas áreas para ocuparem, chegando a região de Auaris, no Brasil. Segundo Sack (1986, p. 21-22),

um local pode ser usado como território em um momento e não mais em outro. Isto significa que, ao criarmos um território, nós também poderemos estar criando um tipo de local. Mas é importante distinguir entre um território como um local e outros tipos de locais. Diferentemente de outros locais comuns, os territórios requerem esforços constantes para estabelecer e mantê-lo. Eles são resultados de estratégias para afetar, influenciar e controlar pessoas, fenômenos e relações. Circunscrevendo coisas no espaço ou em um mapa, como quando um geógrafo delimita uma área para ilustrar onde o milho cresce ou onde a indústria está concentrada, identificar locais, áreas ou regiões no censo comum. Mas não criando propriamente um território. Esta delimitação se torna um território, 
somente quando as suas fronteiras são usadas para afetar o comportamento ou para controlar o acesso [...] as fronteiras da região estão afetando o acesso aos recursos e ao poder. Elas estão moldando o comportamento. E assim o local se torna um território.

Farage e Santilli (2009) apresentam, a partir dos relatos de Manoel da Gama Lobo D'Almada (1787) e Rodrigues Ferreira (1786), a localização aproximada dos povos indígenas que ocupavam a bacia do rio Branco no século XVIII. Nesse registro os Macuxi habitavam a região que se estendia do rio Rupununi (na Guiana) em direção a oeste até o rio Surumu, com destaque para o rio Cotingo (afluente do rio Surumu) e do rio Maú, a leste do atual estado de Roraima. Pouco mais de um século depois, em 1911/1912, Koch-Grünberg (2006) aponta como uma das localizações dos Macuxi a Ilha de Maracá, no médio rio Uraricoera. Para o viajante,

perseguições e atos de violência por parte de colonos brancos, que começaram a se estabelecer naquela parte do rio nos últimos 30 anos, assim como [diversas] epidemias têm transformado a vila num deserto e dizimado e dispersado os seus moradores. Uns poucos remanescentes deles vivem ainda, aqui e acolá, na e perto de Maracá em pequenas cabanas (KOCH-GRÜNBERG, 2006, p. 37).

Assim, de acordo com os dois levantamentos, percebe-se que os Macuxi realizaram deslocamentos espaciais, ocupando outras áreas. Esse deslocamento não significa que o antigo território tenha ficado vazio de indivíduos dessa etnia, como é, também, o caso dos Ye'kuana, mas que novos territórios foram criados, isto é, ocorre a reconstrução de um território em uma área onde seja possível a reprodução física e cultural do grupo. Para Baines (2004, p. 71),

\begin{abstract}
A ocupação do lavrado de Roraima se consolidou com a construção do Forte São Joaquim, no rio Branco, em 1775-1776. O desejo das elites de consolidar uma população nacional unificada em torno de valores culturais europeus foi imposto através de políticas de "integração" cultural expressas em miscigenação (1861 [1787]) implantadas no rio Branco por Lobo de Almada. Os povos indígenas enfrentaram políticas de invasão e ocupação dos seus territórios por agentes sociais enviados pelo Estado (soldados, missionários, comerciantes, professores e administradores).
\end{abstract}

Os Macuxi, que ocupavam a área do lavrado do rio Branco, passaram por processos diversos de ocupação de seus territórios e de reconstrução do mesmo. No final do século XIX e início do XX ocorreram levas de migrantes civis que passaram a ocupar o vale do rio Branco com a pecuária e, nas décadas seguintes os garimpeiros se ocuparam das regiões do rio Cotingo, Maú e Suapi, com um movimento de grupos humanos. Na década de 1930 o 
garimpo surge em uma nova área, na Serra do Tepequém (a oeste do estado de Roraima) e atrai centenas de pessoas em busca de riqueza. Porém, desde o século XVIII a população indígena ficou recuada a pequenas áreas e estava, gradativamente, perdendo espaço nos campos do rio Branco, transferindo-se para a região da Fazenda Nacional São Marcos.

Em seus levantamentos, Barbosa (1993) destaca que o fato da Fazenda São Marcos passar a ser administrada pelo Serviço de Proteção aos Índios/SPI não significou que estava destinada a um trabalho com os índios, uma vez que este não era o seu propósito. O que ocorreu foi uma situação em que a Fazenda São Marcos estava em uma área onde habitavam indígenas e o SPI era o responsável por essa parcela da população e, assim, a fazenda se tornou um ponto administrativo, uma base operativa para os funcionários do órgão mais do que algo realmente em favor dos indígenas. A área da Fazenda São Marcos corresponde, atualmente, a terra indígena que leva o mesmo nome e localiza-se nas margens do rio Uraricoera, em seu baixo curso já próximo do encontro com o rio Tacutu e a formação do rio Branco. Os grupos apontados por Barbosa (1993), das etnias Macuxi, Wapixana e Taurepang estão, assim, não muito próximo das áreas indicadas por Lobo D' Almada no século XVIII ou Koch-Grünberg no início do século XX (Figura 1).

Figura 1: Locais aproximados de ocupação dos povos indígenas em Roraima.

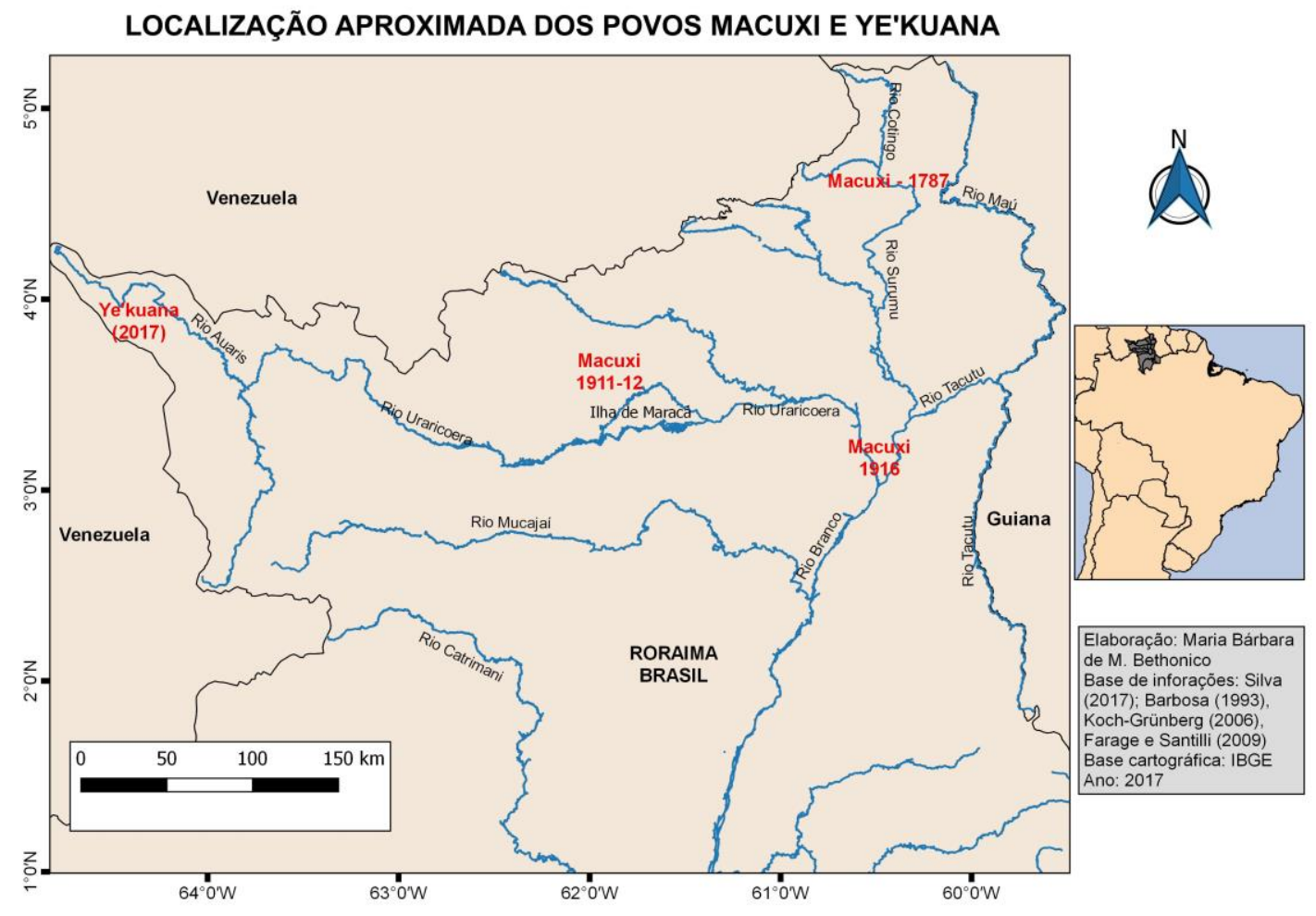


O deslocamento das populações indígenas e a construção de novos territórios está, geralmente, relacionada a escassez de recursos naturais (devido a formas de manejo ou crescimento populacional), às pressões externas como a chegada dos não índios, ou mesmo por conflitos com outros grupos étnicos. Assim, em momentos anteriores à demarcação de áreas voltadas para os povos indígenas, estes ocupavam espaços que tinham o controle sobre ele, a decisão de mudança e a escolha do novo local vinculava-se aos mitos e crenças ou a disponibilidade de recursos. Essa situação começou a se modificar com a chegada de fazendeiros, garimpeiros, cidades e a efetivação das ações estatais como a construção de infraestrutura para atender às demandas capitalistas. A efetivação dessa expansão nos moldes capitalistas e com o apoio do Estado traz uma nova realidade para os povos indígenas, principalmente com a formação das terras indígenas.

\section{2 - TERRA INDÍGENA}

Dallari (2012) ao informar sobre a situação de terras indígenas, destaca que trata-se de terras da União, como apontado na Lei das Terras (Lei n. 601, de setembro de 1850), que dispõe sobre as terras devolutas no Império. Essas terras, que incluíam as ocupadas por comunidades indígenas foram, assim, integradas ao Império e transformadas em patrimônio da União com o advento da República. No Art. 12 da Lei n. 601/1850 define-se que o governo deverá reservar as terras devolutas que julgar necessárias para, dentre outros fins, o de colonização dos indígenas.

A Lei n. 6.001 de 1973, conhecida como Estatuto do Índio, vem regulamentar a situação jurídica dos índios e de suas comunidades. A intenção, segundo disposto no Art. $1^{\circ}$, é de "preservar a sua cultura e integrá-los, progressiva e harmoniosamente, à comunhão nacional”. A possibilidade de viver em seu espaço está previsto no Art. $2^{\circ}$, quando o Estado deve garantir a permanência voluntária e proporcionar os recursos para o seu "desenvolvimento e progresso", considerando que as "peculiaridades inerentes à sua condição" devem ser respeitadas. Neste mesmo artigo é apresentada a garantida aos índios e comunidades com a "posse permanente das terras que habitam, reconhecendo-lhes do direito ao usufruto exclusivo das riquezas naturais e de todas as utilidades naquelas terras existentes" (Art. $2^{\circ}$, inciso IX). Para tal, considera-se como terra indígena as áreas ocupadas pelos 
"silvícolas" " e as sob domínio de uma comunidade indígena. Essas áreas não podem ser arrendadas ou negociadas de forma a restringir a posse dos habitantes da área.

No século XX, a ideia de proteção aos índios consta no Código Civil de 1916, que estabelece a "incapacidade relativa dos índios", comparados aos menores de idade e, por isso, necessitam ser tutelados até que fossem integrados à sociedade, isto é, à "civilização do país". A Constituição da República de 1934 apresenta, em seu Art. 129, o respeito à posse de terras para os índios que habitam no espaço de forma permanente, não sendo permitido a alienação. Segundo informações disponibilizadas no site da Fundação Nacional do Índio ${ }^{2}$, a Constituição de 1934 procedeu a formalização dos direitos dos índios sobre a terra, porém em uma situação de constante conflito de competências entre a União e os estados. Esse conflito foi solucionado com o Estatuto do Índios em 1973.

Importante destacar que a demarcação de áreas para os índios têm registro anteriores ao ano de 1973. O Parque Indígena do Xingu foi criado em 1961, no final de um longo processo que iniciou-se nos anos de 1950, momento em que interesses imobiliários pressionavam por terras no Mato Grosso. Apesar do avanço no que se refere aos direitos dos índios a uma terra (como definido alguns anos depois), a delimitação dessa área não conseguiu contemplar todo o território dos índios que ali ocupavam tradicionalmente ${ }^{3}$.

A Constituição Federal de 1988 reforça o papel do Estado como responsável pela demarcação de terras indígenas, sendo que estas devem ser adequadas à reprodução física e cultural do povo ou povos que nelas habitarem. A perspectiva assimilacionista, presentes em documentos anteriores, já não era contemplada com o novo texto constitucional de 1988, sendo reconhecidas as diferenças entre os povos, sem fazer menção a ideia da tutela. De acordo com Araújo e Leitão (2002, p. 24) uma inovação foi o reconhecimento da "capacidade processual dos índios, suas comunidades e organizações" no que se refere à defesa dos direitos e interesses. Trouxe, também, a necessidade de reformulação (ainda em andamento)

1 De acordo com a Lei n. 6.001/73, Art. $3^{\circ}$ : "I - Índio ou Silvícola - É todo indivíduo de origem e ascendência pré-colombiana que se identifica e é identificado como pertencente a um grupo étnico cujas características culturais o distinguem da sociedade nacional; II - Comunidade Indígena ou Grupo Tribal - É um conjunto de famílias ou comunidades índias, quer vivendo em estado de completo isolamento em relação aos outros setores da comunhão nacional, quer em contatos intermitentes ou permanentes, sem contudo estarem neles integrados".

2 Informações disponíveis em: <http://www.funai.gov.br/index.php/servico-de-protecao-aos-indiosspi?start=4>. Acesso em: 18 ago 2017.

3 Informações disponíveis em: <http://axa.org.br/anexo/no-ponto-sociedade/ >. Acesso em: 18 ago 2017. 
do Estatuto do Índio, Lei 6.001 de 1973, uma vez que este tem como bases a noção de tutela e a concepção de que os índios devem ser assimilados à sociedade nacional.

Diante da expansão capitalista no estado de Roraima e do risco de perderem os espaços que ainda ocupavam, no ano de 1988, com a Constituição Federal, as populações indígenas construíram esperanças no que se refere à demarcação de suas terras e a saída dos não-índios. Em Roraima a presença de fazendeiros em áreas antes ocupadas por comunidades indígenas era um fato comum (o que não diferenciava de outras partes do Brasil) e existem vários relatos de como era a relação, muitas vezes marcadas por conflitos e situações de violência na disputa pela terra e os recursos ali existentes. Esse é o caso relatado por Montanha (1994) ao falar do Oixi, localidade a leste do que hoje é a Terra Indígena Raposa Serra do Sol. Segundo o autor,

saiu a promulgação da nova Constituição Federal do Brasil [...] os índios fizeram festança para comemorar o fato. Dias depois Aniceto trouxe o texto da Constituição para a maloca e leu parágrafo por parágrafo o capítulo dos índios. E explicou que, de acordo com a nova Carta Magna, o governo federal deveria demarcar todas as terras indígenas no prazo máximo de cinco anos. Até dia 5 de outubro de 1993. Entretanto, os dias foram passando e as coisas continuaram do mesmo jeitinho em Oixi. Nada mudou, nadinha. $\mathrm{O}$ vale de esperança tinha se transformado definitivamente num lago de lágrimas, de dúvidas, de intranquilidade, de medo (MONTANHA, 1994, p. 150).

Aos poucos perceberam, assim, as enormes dificuldades que continuariam enfrentando por mais vinte e um anos até a decisão final do Supremo Tribunal Federal sobre a demarcação e homologação da Terra Indígena Raposa Serra do Sol em formato contínuo.

O reconhecimento do direito à terra, entendida como espaço necessário à sobrevivência dos indígenas, tem um longo caminho na legislação brasileira. Um das questões que pretendemos abordar neste artigo é a definição do que seja uma terra indígena. Para tal, consideramos que trata-se de um conceito jurídico, isto é, uma determinação prevista em um texto normativo emanado pelo Estado. A terra indígena tem seu conceito antropológico e cultural, mas a partir do momento em que está prevista na Constituição, passou a ser um conceito jurídico, trazendo consigo a necessidade de definição clara para que o próprio Estado possa operacionalizá-lo.

Trata-se, dessa forma, de um conceito utilizado pelo Estado e que tem caráter jurídico, explícito na Constituição Federal de 1988, que em seu Art. 231 reconhece a organização social, costumes, línguas, crenças e tradições dos índios e os direitos originários sobre as 
terras que ocupam. A própria Constituição já apresenta alguns elementos que caracterizam uma terra indígena, como a responsabilidade da União de demarcá-las e protegê-las, sendo estas terras inalienáveis, indisponíveis e os direitos sobre elas imprescritíveis. Assim, as terras indígenas são bens da União com usufruto dos povos indígenas e não podem ser vendidas, trocadas ou negociadas. O Decreto n. 1.775/96 dispõe sobre os procedimentos administrativos referentes a demarcação das terras indígenas. Essa função é atribuída ao órgão federal de assistência ao índio, no caso a Fundação Nacional do Índio/FUNAI. Com referência do que é uma terra indígena, ainda utilizam a Lei n. 6.001 de 1973 (conhecida como Estatuto do Índio) que, em seu art. $2^{\circ}$ inciso IX escreve "garantir aos índios e comunidades indígenas, nos termos da Constituição, a posse permanente das terras que habitam, reconhecendo-lhes o direito ao usufruto exclusivo das riquezas naturais e de todas as utilidades naquelas terras existentes". Nesse contexto,

\begin{abstract}
o direito dos grupos tribais de ter acesso à terra é reiteradamente afirmado (art. $2^{\circ} \S$ 9 , arts. 17 a 38 , art. 62), ficando igualmente explicitado que não se trata apenas de resguardar o local de moradia ou outros de significação simbólica (cemitérios, lugares míticos, etc.), mas de garantir a terra como um meio de produção necessário (arts. 26, 27 e 28). Assim fica estabelecido que as áreas reservadas - onde poderá se tornar mais explícita a diretiva do indigenismo oficial - serão terras destinadas à posse e ocupação permanente pelos índios, suficientes para que 'possam viver e obter meios de subsistência, com direito ao usufruto e utilização das riquezas naturais dos bens nelas existentes, respeitadas as restrições legais' (art. 26) (OLIVEIRA, 1998, p. 19).
\end{abstract}

Segundo Badin (2006) considerar o conceito constitucional de terra indígena implica em uma abordagem jurídica, porém, esta é apenas uma das faces a ser estudada, considerando a complexidade do conceito. A terra indígena tem um vínculo com o território em que vivem os índios, sendo que essa base territorial implica na sobrevivência física e cultural do povo, daí a importância que esses grupos conferem à demarcação de suas terras. Ao serem demarcadas e homologadas essas terras passam a obedecer um regime especial que tem como base: inalienável, indisponível e os direitos sobre ela são imprescritíveis; aos índios é assegurado o usufruto exclusivo das riquezas naturais do solo e, no que se refere ao subsolo, a exploração dos recursos naturais depende de aprovação do Congresso Nacional. Para esse autor, existem quatro dificuldades de definição dos requisitos para que o Estado determine que parte do seu território seja destinado a um determinado povo: i) exige uma mudança de perspectiva cultural, quando considera que esse direito à terra está vinculado aos usos, 
costumes e tradições, diferente do que está previsto no Código Civil; ii) o conceito de terra indígena traz como referência elementos científicos: históricos, antropológicos, sociais e biológicos, situação que dificulta as análises dos juristas; iii) trata-se de um conceito abrangente e que exige rigor por parte dos tomadores de decisões, pois a demarcação de uma terra indígena atinge situações sociais que estão consolidadas ao longo dos anos; iv) existem poucos estudos jurídicos consistentes sobre a matéria.

Ao ser demarcada, homologada e registrada, uma terra indígena deveria significar o habitat de um povo, o espaço necessário ao desenvolvimento da sua sociedade, diferindo da propriedade privada como abordada pelo Código Civil brasileiro, onde existe um poder sobre um determinado espaço e o direito ao proprietário de dispor do bem quando julgar necessário. No caso das terras indígenas, a partir do momento em que são indisponíveis, não existe a possibilidade de disporem do espaço a eles reservado pelo Estado e, com isso, a mobilidade espacial e a constituição de novos territórios fica limitada a um limite imposto pelo Estado, bem como a exploração dos recursos minerais. Isso, ao longo do tempo, tem trazido sérios problemas para esses grupos, uma vez que ocorre um expressivo crescimento populacional e a escassez de recursos naturais para pesca e caça, principalmente quando observamos as terras indígenas que foram demarcadas em formato de ilha, isto é, são pequenas áreas e no entorno encontram-se fazendas, unidades de conservação, áreas públicas, projetos de assentamentos ou mesmo, outra terra indígena.

Para Araújo e Leitão (2002), o moroso processo de reformulação do Estatuto do Índio não tem impedido que avanços ocorram no que se refere aos direitos indígenas e sua relação com o Estado. Destacam a ratificação da Convenção 169 da Organização Internacional do Trabalho/OIT em 2002, enquanto instrumento internacional que vem tratar com dignidade os direitos coletivos dos povos indígenas e estabelece alguns pontos para serem seguidos pelo Estado. Em seu artigo 14, esta convenção indica que cabe aos governos adotarem as medidas necessárias para a determinação das terras aos povos indígenas bem como a garantia da proteção efetiva de seus direitos de posse. No que se refere ao uso dos conceitos terra e território, a Convenção n. 169 da OIT que aborda o tema povos indígenas e tribais, adotada em Genebra no ano de 1989, traz que o termo "terras" inclusos nos Artigos 15 e 16, deve conter o conceito de território, sendo este compreendido como a totalidade do habitat dos povos em questão (DECRETO n. 5051 DE 2004).

O Art. 231 da Constituição Federal trata de "terras tradicionalmente" ocupadas pelos 
índios como a base para a identificação e demarcação de uma terra indígena. Badin (2006), ao citar o Ministro Victor Nunes Leal do Supremo Tribunal Federal, no ano de 1961, em situação de questionamento de área tradicionalmente ocupada por índios no estado do Mato Grosso, observa que uma terra tradicionalmente ocupada reflete uma situação de transmissão cultural que avança por gerações, um legado cultural transmitido de pai para filho. Assim, o reconhecimento dessas terras deve obedecer todo o processo administrativo de demarcação para que se torne válida e regular, obedecendo todo o rigor científico estabelecido pela Portaria/FUNAI n 14, de 09 de janeiro de 1996, que estabelece regras para a elaboração do Relatório de identificação e delimitação de terras indígenas.

Araújo e Leitão (2002, p. 28) apontam que as políticas públicas voltadas aos povos indígenas no Brasil apresentam um grau de esquizofrenia que é consequência de uma convivência entre um texto constitucional avançado em termos de conceitos e relações políticas com os povos indígenas, porém, com regras ainda ditadas pelo Estatuto do Índio de 1973, que possui conceitos superados. Para os autores, apesar dessa situação, devemos reconhecer os avanços no que se refere aos processos de demarcação das terras indígenas, principalmente quando consideramos a expansão da fronteira capitalista na Amazônia.

Cabe destacar um item que define o uso das terras indígenas pela população que ali habita: o usufruto. Ao discutir a contradição entre propriedade privada e Estado capitalista, Harvey (2016) define a propriedade privada como o direito de posse exclusivo sobre algo ou algum processo e esse direito inclui a possibilidade de vender ou alienar a propriedade. $\mathrm{O}$ usufruto corresponde ao direito de uso ativo e da propriedade exclusiva e permanente. Para o autor:

as potências coloniais costumavam impor direitos exclusivos de propriedade, o que gerou muitos conflitos. Populações que se deslocavam de um lugar para outro, acompanhando rebanhos ou trocando uma terra esgotada por outras mais férteis, viram-se impedidas de repente de se locomover por causa de cercas e arames farpados. Foram proibidas muitas vezes de usar terras que tradicionalmente consideravam livres para o uso porque agora alguém a possuía perpetuamente, mesmo que não a usasse (HARVEY, 2016, p. 48).

Os direitos sobre uma propriedade são concedidos tanto para pessoas físicas quanto para jurídicas; estes dispõe do bem como julgarem melhor e esses direitos são mantidos perpetuamente, mesmo que não façam nenhum uso da propriedade e que seja a propriedade da terra, entendida aqui como essencial à reprodução da vida. A garantida desse direito é de 
responsabilidade do Estado que é, também, o legalizador quando constitui os sistemas legais.

Na decisão do Supremo Tribunal Federal de março de 2009, foram definidas dezenove condicionantes para o caso da Terra Indígena Raposa Serra do Sol. Dentre elas, cinco abordam especificamente a questão do usufruto, deixando exposto o controle do espaço pelo Estado e não pelos índios e comunidades que ali habitam:

1 - O usufruto das riquezas do solo, dos rios e dos lagos existentes nas terras indígenas pode ser relativizado sempre que houver como dispõe o artigo 231 (parágrafo $6^{\circ}$, da Constituição Federal) o relevante interesse público da União na forma de Lei Complementar;

2 - O usufruto dos índios não abrange o aproveitamento de recursos hídricos e potenciais energéticos, que dependerá sempre da autorização do Congresso Nacional; 3 - O usufruto dos índios não abrange a pesquisa e a lavra das riquezas minerais, que dependerá sempre de autorização do Congresso Nacional, assegurando aos índios participação nos resultados da lavra, na forma da lei.

4 - O usufruto dos índios não abrange a garimpagem nem a faiscação, devendo se for o caso, ser obtida a permissão da lavra garimpeira;

5 - O usufruto dos índios não se sobrepõe ao interesse da Política de Defesa Nacional. A instalação de bases, unidades e postos militares e demais intervenções militares, a expansão estratégica da malha viária, a exploração de alternativas energéticas de cunho estratégico e o resguardo das riquezas de cunho estratégico a critério dos órgãos competentes (o Ministério da Defesa, o Conselho de Defesa Nacional) serão implementados independentemente de consulta a comunidades indígenas envolvidas e à Funai (SUPREMO TRIBUNAL FEDERAL, 2017).

No caso dos povos indígenas de Roraima, é comum escutar ou ver em algum lugar registrado a fala de "muita terra para pouco índio", referindo-se a forma como usam o espaço concedido pelo Estado na forma de terra indígena. Essa fala vem de encontro com a concepção de que a terra tem que ser utilizada, justificando a espoliação das populações indígenas que ocorreu anteriormente e, atualmente quando se questiona as dimensões de algumas terras indígenas, como a Raposa Serra do Sol que, no processo de retirada dos arrozeiros (situação definida pelo Supremo Tribunal Federa), foi fala recorrente nos discursos dos fazendeiros e governo do estado de Roraima que lutavam contra a demarcação em formato contínuo.

\section{CONSIDERAÇÕES FINAIS}

Ao abordar a atual situação dos povos indígenas no Brasil nos deparamos com questões conceituais que necessitam de amadurecimento para que os termos sejam usados adequadamente, não apenas no campo acadêmico mas, também, no âmbito das políticas 
públicas voltadas para a organização do território brasileiro de forma a clarear um posicionamento frente as comunidades. Por outro lado, os próprios indígenas falam de dúvidas sobre qual termo usar para definir o local onde vivem, se usam território ou terra indígena.

Acreditamos que a Geografia, entendida como ciência espacial e que traz a complexidade como característica, pode contribuir para a discussão sobre os conceitos de terra indígena, território e território indígena. Essa contribuição deve-se, principalmente, pelo fato dos estudos espaciais permitirem diálogos com outras áreas de conhecimento, como a História e a Antropologia, por exemplo. O contexto histórico dos povos indígenas é importante para compreender a formação dos territórios, onde conseguem realizar sua reprodução, garantindo a sobrevivência do grupo e, também do seu aniquilamento. Por outro lado, a História nos traz informações sobre a dinâmica espacial, na junção do tempo com o espaço e, nesse sentido, permite compreender as influências do sistema capitalista, do Estado e, também, a própria cultura dos povos indígenas na atual configuração espacial que temos na Amazônia. Os relatos de viajantes de séculos atrás; os documentos oficiais e levantamentos bibliográficos permitiram compreender como estavam distribuídos os diversos grupos étnicos na região do rio Branco, no extremo norte do Brasil, identificando os territórios constituídos pelos povos e os movimentos que realizavam decorrentes de diversos fatores, tanto internos quanto externos.

Para a Geografia o conceito de território liga-se a uma ação que é conduzida por um ator ou por atores, gerando a apropriação de um determinado espaço, situação em que são atribuídos poder às coisas e aos homens. Um território pressupõe uma referência espacial, como o local onde se vive, um ambiente controlado e com a existência de um poder "sem inocência" que vem marcar as relações de uma sociedade.

Pressupõe, assim, que um espaço é considerado como território a partir de relações que se estabelecem para o controle de pessoas e dos recursos naturais disponíveis. Esse controle relaciona-se a uma situação de autonomia para decisões sobre o uso do espaço e as forma organizativas. A localização e usos do território pode ser conferida a um povo por seus ancestrais e entidades míticas, como é o caso do povo Ye'kuana, ou mesmo forças externas a um grupo podem gerar o abandono de uma área já de domínio para outro espaço, com a constituição de um território com nova base espacial, como é o caso do povo Macuxi. Porém, cabe destacar, que as relações que se estabelecem entre esses grupos e os demais são definidas 
pelos próprios membros e integrantes sociais e não por grupos ou entidades externas. As necessidades e outras pressões externas podem promover novos deslocamentos e, consequentemente, a constituição de novos territórios ou mesmo a expansão de um já existente. Assim, ao resgatar relatos históricos, percebemos que os povos indígenas formavam seus territórios e os identificavam através da história do povo, das indicações das entidades espirituais e, também, pela possibilidade do espaço suprir as necessidades de sobrevivência do grupo. Consideram que o território é a fonte da vida e está vinculado a um sentimento de pertencimento.

O Estado brasileiro, justificando-se com o necessário ordenamento de seu território, alterou essa lógica presente entre os povos indígenas quando faz a opção pelo capitalismo e pela propriedade privada, limitando os espaços de deslocamento dos índios como tradicionalmente sempre ocorreu. Estabeleceu, assim, limites fixos para os grupos quando cria as terras indígenas. Além dos limites físicos que, muitas vezes abriga povos diferentes, existem os limites de uso sobre os recursos naturais disponíveis, principalmente os minerais, situação que coloca novos elementos para se pensar em territórios indígenas atualmente. As terras indígenas obedecem as normas do Estado e impõe aos povos indígenas essas regras como contrapartida para habitarem nessas terras, espaços de sobrevivência ou "reprodução física e cultural", levando aos diversos grupos o exercício de repensar novas formas e referências espaciais de constituição do território.

O ordenamento do território de um Estado não consegue lidar com deslocamentos de grupos, uma vez que a terra, de acordo com os ordenamentos jurídicos, possui proprietários e o próprio Estado é o guardião do direito à propriedade privada. Como aceitar, ou mesmo permitir, que grupos se desloquem sobre o espaço em busca de novos recursos, como sempre fizeram de forma tradicional por considerarem que a terra é um bem comum e não propriedade? Diante desse dilema, o Estado passou a determinar espaços limitados, as terras indígenas, para esses deslocamentos de forma que ele mesmo consiga gerenciá-los com suas regras ou pela legislação. No caso dos Macuxi, por exemplo, temos uma situação de divisão do povo em várias terras indígenas, tanto as demarcadas em formato contínuo, como a Raposa Serra do Sol e São Marcos, como as em ilha que formam um mosaico na região do lavrado roraimense. Para as comunidades e povos indígenas restam os problemas de gestão da terra, um desafio no momento em que passam por situações de crescimento expressivo da população e, nesta situação, a caça, a pesca e os locais de roça se tornam insuficientes para 
atender a todos.

Destaca-se que os homens necessitam de um território para viver e, nesse sentido, observamos que nas comunidades localizadas em terras indígenas existe um esforço nesse sentido, ao buscarem a constituição de um território, de ter um controle sobre o espaço vivido e ocupado, porém, esbarram nas amarras do Estado que acaba por ter mais controle do que os próprios índios. Mesmo com as questões apontadas acima, consideramos que a demarcação das terras indígenas representa um avanço no que se refere aos direitos de um povo e que trouxe segurança para diversos grupos. Cabe a esses povos superarem essas amarras do Estado e buscarem, juntos, a autonomia sobre seus espaços e os novos territórios que ainda estão em construção.

\section{REFERÊNCIAS BIBLIOGRÁFICAS}

ARAÚJO, A. V.; LEITÃO, S. Direitos indígenas: avanços e impasses pós-1988. In: LIMA, A. C. S.; BARROSO-HOFFMANN, M. Além da tutela: bases para uma nova política indigenista III. Rio de Janeiro: Contracapa Editora, 2002. p. 23-33.

BADIN, L. A. Sobre o conceito constitucional de terra indígena. Arquivos do Ministério da Justiça. Brasília, ano 51, n. 190, p. 127-141, Jul./dez.2006.

BAINES, S. G. A fronteira Brasil-Guiana e os povos indígenas. Revista de Estudos e Pesquisas-FUNAI, Brasília, v. 1. n. 1,p. 65-98, jul. 2004.

BARBOSA, R. I. Ocupação humana em Roraima I: do histórico colonial ao início do assentamento dirigido. Boletim do Museu Paraense Emílio Goeldi. Belém, n. 9 (2), p. 177 $197,1993$.

DALLARI, D. Terras indígenas e falsos proprietários. Jornal do Brasil, Rio de Janeiro, 10 de nov. 2012. Disponível em:

<http://www.revistaforum.com.br/mariafro/2012/11/10/dalmo-dallari-terras-indigenas-efalsos-proprietarios/>. Acesso em 14 nov. 2016.

DANTAS, E. M.. Caminhos de uma Geografia complexa. In: SILVA, A. A. D.; GALENO, A. (Orgs.). Geografia: ciência do complexus: ensaios transdisciplinares. Porto Alegre: Sulina, 2004. p. 237-252.

FARAGE, N. SANTILLI, P. TI Raposa Serra do Sol: fundamentos históricos. In: MIRAS, J. T. et. al. Makunaima grita: Terra Indígena Raposa Serra do Sol. Rio de Janeiro: Beco do Azougue, 2009. p. 21-30.

FUNAI/Fundação Nacional do Índio. Modalidades de terras indígenas. Disponível em: 
$<$ http://www.funai.gov.br/index.php/indios-no-brasil/terras-indigenas $>$. Acesso em: 14 nov. 2016.

HAESBAERT, R. O mito da desterritorialização: do "fím dos territórios" à multiterritorialidade. Rio de Janeiro: Bertrand Brasil, 2004. 396 p.

HARVEY, D. 17 contradições e o fim do capitalismo. São Paulo: Boitempo, 2016. 302 p.

KOCH-GRÜNBERG, T. A distribuição dos povos entre rio Branco, Orinoco, rio Negro e Yapurpá. Manaus: Editora INPA/EDUA, 2006. 151 p.

MOINE, A. Le territoire comme un système complexe: un concept opératoire pour l'aménagement et la géographie. L'Espace Géographique, França, v. tomo 35, n. 2, p. 115-132, 2006.

MONTANHA, V. Os bravos de Oixi: índios em luta pela vida. Petrópolis: Vozes, 1994. 232 p.

OLIVEIRA, J. P. Redimensionando a questão indígena no Brasil: uma etnografia das terras indígenas. In: OLIVEIRA, J. P. (Org.). Indigenismo e territorialização: poderes, rotinas e saberes coloniais no Brasil contemporâneo. Rio de Janeiro: Contra Capa, 1998. cap. 1, p. 1542 .

RAFFESTIN, C. Por uma geografia do poder. São Paulo: Ática, 1993. 269 p.

ROUX, M. O re-encantamento do território. In: SILVA, A. A. D. da; GALENO, A. (Orgs.). Geografia ciência do complexus: ensaios transdisciplinares. Porto Alegre: Sulina, 2004. p. 42-66.

SACK, R. D. Territorialidade Humana: sua teoria e história. Cambridge University Press, 1986. Disponível em: <http://pt.scribd.com/doc/122070781/Sack-Robert-DavidTerritorialidade-Humana-sua-teoria-e-historia>. Acesso em: 19 mai 2017.

SANTOS, M. O retorno do território. In: OSAL/Observatorio Social de América Latina Debates, Buenos Aires: CLACSO, año 6, n. 16, p. 251-261, enero 2005.

SILVA, C. C. Transformações socioespaciais das comunidades indígenas Ye'kuana e Sanumã na região de Auaris-Roraima. Dissertação (Mestrado em Geografia) Departamento de Geografia, Universidade Federal de Roraima, Boa Vista, 2017.

Supremo Tribunal Federal/STF. STF impõe 19 condições para demarcação de terras indígenas. Supremo Tribunal Federal, Brasília, 19 mar. 2009. Disponível em: <http://www.stf.jus.br/portal/cms/verNoticiaDetalhe.asp?idConteudo=105036>. Acesso em: 19 ago 2017. 